\title{
SOME FURTHER RESULTS ON LEGENDRE NUMBERS
}

\section{PAUL W. HAGGARD}

Department of Mathematics, Last Carolina University

Greenville, North Caroline 27858 U.S.A.

(Received February 12, 1987)

ABSTRACT. The Legendre numbers, $\mathrm{P}_{\mathrm{n}}^{\mathrm{m}}$, are expressed in terms of those numbers, $\mathrm{P}_{k}^{\mathrm{m}-1}$, in the previous column down to $\mathrm{P}_{\mathrm{n}}^{\mathrm{m}}$ and in terms of those, $\mathrm{P}_{\mathrm{k}}^{\mathrm{m}}$, above but in the same column. Other results are given for numbers close to a given number. The limit of the quotient of two consecutive non-zero numbers in any one column is shown to be -1. Bounds for the Legendre numbers are described by circles centered at the origin. A connection between Legendre numbers and Pascal numbers is exhibited by expressing the Legendre numbers in terms of combinations.

KEY WORDS AND PHARASES. Associated Legendre functions, bounds for the Legendre numbers, Legendre numbers, Legendre polynomials, limits of ratios of Legendre numbers. 1980 MATHEMATICS SUBJECT CLASSIFICATION CODES. 10A40, 26C99, 33A45.

\section{INTRODUCTION.}

The Legendre numbers were introduced in [1] and several elementary properties were given. In [2], some applications of the numbers were presented. Further applications are needed. In this note some relationships between the numbers are shown, bounds are given for the numbers, and the numbers are described in terms of combinations. For reference, we give (from [1]) the definition that we use, a general formula for the numbers, and a partial table of them.

Definition 1. The Legendre numbers, $P_{n}^{m}$, are the values of the associated Legendre functions, $P_{n}^{m}(x)$, for $x=0$ and $m$, $n$ non-negative integers.

A general formula for the Legendre numbers is

$$
\mathrm{p}_{\mathrm{n}}^{\mathrm{m}=}\left\{\begin{array}{l}
0, \mathrm{~m}+\mathrm{n} \text { odd } \\
0, \mathrm{~m}>\mathrm{n} \\
\frac{(-1)^{\frac{\mathrm{n}-\mathrm{m}}{2}}(\mathrm{n}+\mathrm{m}) !}{2^{\mathrm{n}\left(\frac{\mathrm{n}+m}{2}\right) !\left(\frac{n-m}{2}\right) !}, \mathrm{m}+\mathrm{n} \text { even, } \mathrm{m} \leq \mathrm{n} .}
\end{array}\right.
$$

Another result needed is that

$$
P_{n}^{m}=P_{n}^{(m)}(0)
$$

where $P_{n}^{(m)}(0)$ is the mth derivative of the Legendre polynomial, $P_{n}(x)$, evaluated at $\mathrm{x}=0$.

2. SOME RELATIONSHIPS BETWEEN LEGENDRE NUMBERS.

Many relationships between Legendre numbers have been shown in [1], and [2]. 
Here, each Legendre number is expressed in terms of the non-zero entries in the previous colum (see Table 1) down to this entry in two ways. Further, each is expressed in terms of the non-zero entries in the same colum but above the entry.

\begin{tabular}{|c|c|c|c|c|c|c|c|c|c|}
\hline${ }_{n} \cdot P_{n}^{n}$ & $P_{n}=P_{n}^{0}$ & $\mathrm{P}_{\mathrm{n}}^{1}$ & $\mathrm{p}_{\mathrm{n}}^{2}$ & $\mathrm{P}_{\mathrm{n}}^{3}$ & $\mathrm{P}_{\mathrm{n}}^{4}$ & $\mathrm{P}_{\mathrm{n}}^{5}$ & $\mathrm{P}_{\mathrm{n}}^{6}$ & $\mathrm{P}_{\mathrm{n}}^{7}$ & $\mathrm{P}_{\mathrm{n}}^{8} \quad \cdots$ \\
\hline 0 & 1 & & & & & & & & \\
\hline 1 & 0 & 1 & & & & & & & \\
\hline 2 & $-\frac{1}{2}$ & $\begin{array}{l}0 \\
3\end{array}$ & 3 & & & & & & \\
\hline 3 & 0 & $-\overline{2}$ & 0 & 15 & & & & & \\
\hline 4 & $\frac{3}{8}$ & 0 & $-\frac{15}{2}$ & 0 & 105 & & & & \\
\hline 5 & 0 & $\frac{15}{8}$ & 0 & $-\frac{105}{2}$ & 0 & 945 & & & \\
\hline 6 & $-\frac{15}{48}$ & 0 & $\frac{105}{8}$ & 0 & $-\frac{945}{2}$ & 0 & 10,395 & & \\
\hline 7 & 0 & $-\frac{105}{48}$ & 0 & $\frac{945}{8}$ & 0 & $\frac{10,395}{2}$ & 0 & 135,135 & \\
\hline $\begin{array}{l}8 \\
\vdots\end{array}$ & $\begin{array}{l}\frac{105}{384} \\
\text {.. . }\end{array}$ & 0 & $-\frac{945}{48}$ & 0 & $\frac{10,395}{8}$ & $0-$ & $\frac{135,135}{2}$ & 0 & $2,027,025$ \\
\hline
\end{tabular}

TABLE 1. LEGENDRE NUMBERS

From the known result, see [3],

$$
P_{n}^{\prime}(x)=\sum_{k=1}^{\left[\frac{n}{2}\right]}(2 n-4 k+3) P_{n-2 k+1}(x),
$$

where $\left[\frac{\mathrm{n}}{2}\right]=\frac{\mathrm{n}}{2}$ is $\mathrm{n}$ is even and $\frac{\mathrm{n}+1}{2}$ if $\mathrm{n}$ is odd, it follows that by taking $\mathrm{m}-1$ derivatives then using (1.2), one has

$$
\mathrm{P}_{\mathrm{n}}^{\mathrm{m}}=\sum_{\mathrm{k}=1}^{\left[\frac{\mathrm{n}-\mathrm{m}+1}{2}\right]}(2 \mathrm{n}-4 \mathrm{k}+3) \mathrm{P}_{\mathrm{n}-2 \mathrm{k}+1}^{\mathrm{m}-1}, \mathrm{~m}, \mathrm{n} \geq 1 .
$$

This gives each Legendre number, $P_{n}^{m}$, as a sum of products involving the Legendre numbers in the preceeding column of Table 1 and above $\mathrm{P}_{\mathrm{n}}^{\mathrm{m}}$. Other such formulas are possible. Four that can be proved (mathematical induction, inducting on $n$ is one way) are:

$$
\begin{aligned}
& P_{2 n}^{2 m}=(-1)^{n-m}(4 m-1) \sum_{k=m}^{n}\left|P_{2 k-1}^{2 m-1}\right|, \\
& P_{2 n+1}^{2 m+1}=(-1)^{n-m}(4 m+1) \sum_{k=m}^{n}\left|P_{2 k}^{2 m}\right|, \\
& P_{2 n}^{2 m}=\frac{(-1)^{n-m}(4 m+1)}{2(n-m)} \sum_{k=m}^{n-1}\left|P_{2 k}^{2 m}\right|, n>m, \\
& P_{2 n+1}^{2 m+1}=\frac{(-1)^{n-m}(4 m+3)}{2(n-m)} \sum_{k=m}^{n-1}\left|P_{2 k+1}^{2 m+1}\right|, n>m .
\end{aligned}
$$

Note that (2.3) and (2.4) give each Legendre number as a product that involves the sum of the absolute values of the entries in the previous column and above the entry of Table 1 specified. Similarly, (2.5) and (2.6) involve the entries in the same 
column but above the entry. Equations (2.4) and (2.6) can be obtained from (2.3) and (2.5), repectively, by replacing $2 \mathrm{n}$ with $2 \mathrm{n}+1$ and $2 \mathrm{~m}$ with $2 \mathrm{~m}+1$. In fact, (2.3) and (2.4) can be combined as

$$
P_{n}^{m}=(-1)^{\frac{n-m}{2}(2 m-1)} \sum_{k=1}^{\left[\frac{n-m+1}{2}\right]}\left|P_{n-2 k+1}^{m-1}\right| \text {, }
$$

while (2.5) and (2.6) can be combined as

$$
\mathrm{P}_{\mathrm{n}}^{\mathrm{m}}=\frac{(-1)^{\frac{\mathrm{n}-\mathrm{m}}{2}}(2 \mathrm{~m}+1)^{\left[\frac{\mathrm{n}-\mathrm{m}}{2}\right]}}{\sum_{k=1}^{n-m}}\left|\mathrm{P}_{n-2 k}^{\mathrm{m}}\right|,
$$

for $m$ and $n$ of the same parity.

There are several results concerning entries in Table 1 that are near each other. These can be easily proved using properties of Legendre numbers or by using (1.1). For example,

$$
P_{n}^{m}=\frac{P_{n-1}^{m+1}+P_{n+1}^{m+1}}{2 m+1}, n \geq m+2
$$

gives each entry in terms of the entries in the next column and just above and below. Each entry in terms of the entries in the previous column and just above and below is given by

$$
P_{n}^{m}=-\frac{(n+m-1)(n-m+2)}{2 m-3}\left(P_{n-1}^{m-1}+P_{n+1}^{m-1}\right), n, m \geq 1
$$

Considering $P_{n}^{m}$ and the nearest entries on slant lines through $P_{n}^{m}$ leads to a determinant type result,

$$
P_{n-1}^{m-1} P_{n+1}^{m+1}-P_{n-1}^{m+1} P_{n+1}^{m-1}=\frac{2(2 n+1)}{(n+m-1)(n-m+2)}\left(P_{n}^{m}\right)^{2}
$$

Next, if we look at a particular non-zero entry and consider the first four nonzero entries above, below, to the left, and to the right, we have

$$
\underset{\mathrm{n}-2}{\mathrm{~m}} \mathrm{P}_{\mathrm{n}+2}^{\mathrm{m}}-\mathrm{P}_{\mathrm{n}}^{\mathrm{m}-2} \mathrm{P}_{\mathrm{n}}^{\mathrm{m}+2}=0, \quad \mathrm{n} \geq 4, \quad 2 \leq \mathrm{m} \leq \mathrm{n}-2
$$

which one can express as above $\cdot$ below = left right.

In [1], it was shown that the sum of the non-zero entries in any column of Table 1 converges. The limit of the ratio of consecutive entries is somewhat surprising. Choose the mth column of Table 1. For $n+m$ even and using (1.1), we have

$$
\frac{P_{n+2}^{m}}{P_{n}^{m}}=-\frac{n+m+1}{n-m+2}=-\frac{1+\frac{m}{n}+\frac{1}{n}}{1-\frac{m}{n}+\frac{2}{n}} .
$$

Therefore,

$$
\lim _{n \rightarrow \infty} \frac{P_{n+2}^{m}}{P_{n}^{m}}=-1
$$

From (2.13) it is clear that the limit approaches -1 from the right for $m=0$ and from the left for $m \geq 1$. It is clear that the limit of the absolute value of the ratios is 1 . 
3. BOUNDS FOR THE LEGENDRE NUMBERS.

From the known bound from [3],

$$
\left|P_{n}(x)\right|<\left[\frac{\pi}{2 n(1-x)}\right]^{\frac{1}{2}} \text {, }
$$

for the Legendre polynomials, $P_{n}(x)$, one has, for $x=0$

$$
\left|P_{n}\right|<\sqrt{\frac{\pi}{2 n}}=\frac{\sqrt{2 \pi n}}{2 n}=\frac{\sqrt{C}}{D}=\frac{\pi}{\sqrt{C}}, n \geq 1
$$

where $C=2 \pi n$ is the circumference of a circle of radius $n$ centered at the origin with $D=2 n$ the diameter of the circle.

In [1], the relationship

$$
P_{n}^{m}=(n+m-1)(n+m-3) \cdots(n-m+3)(n-m+1) P_{n-m}, m \geq 1
$$

was given where $P_{n-m}$ is in the first colum of Table 1. Using (3.2) in (3.3) we have the more general result

$$
\left|P_{n}^{m}\right|<(n+m-1)(n+m-3) \cdots(n-m+3)(n-m+1) \frac{\sqrt{C}}{D}, m \geq 1, n>m,
$$

where $C=2 \pi(n-m)$ is the circumference of a circle of radius $n$ - $m$ centered at the origin with $D=2(n-m)$ the diameter of the circle.

4. LEGENDRE NUMBERS IN TERMS OF COMBINATIONS.

In [2], combinations were expressed in terms of the Legendre numbers. Here, we express the Legendre numbers as combinations. The equation

$$
c(q, i)=\frac{(-1)^{1} q ! 2^{1} p_{q+1}^{q-i}}{(q-i) ! P_{q}^{q}}, i=0 \text { to } q
$$

from [2] becomes

$$
\mathrm{P}_{\mathrm{n}}^{\mathrm{m}}=\frac{(-1)^{\frac{\mathrm{n}-\mathrm{m}}{2}} \mathrm{~m} ! \mathrm{P}_{\frac{\mathrm{n}+\mathrm{m}}{2}}^{\frac{\mathrm{n}+\mathrm{m}}{2}} \mathrm{C}\left(\frac{\mathrm{n}+\mathrm{m}}{2}, \frac{\mathrm{n}-\mathrm{m}}{2}\right)}{\left(\frac{\mathrm{n}+\mathrm{m}}{2}\right) ! 2^{\frac{\mathrm{n}-\mathrm{m}}{2}}},
$$

after solving for $\mathrm{P}_{\mathrm{q}+i}^{\mathrm{q}-i}$ then letting $\mathrm{n}=\mathrm{q}+i$ and $m=q-i$. Notice that $\frac{n-m}{2}=i$ and $\frac{n+m}{2}=q$. Since $P_{n}^{n}=1 \cdot 3 \cdot 5 \cdots(2 n-1)$, see $[1]$,

$$
\begin{aligned}
\mathrm{P}_{\frac{\mathrm{n}+\mathrm{m}}{2}}^{\frac{\mathrm{n}+\mathrm{m}}{2}} & =1 \cdot 3 \cdot 5 \cdots(\mathrm{n}+\mathrm{m}-1) \\
& =\frac{(\mathrm{n}+\mathrm{m}) !}{2^{\frac{\mathrm{n}+\mathrm{m}}{2}}\left(\frac{\mathrm{n}+\mathrm{m}}{2}\right) !} .
\end{aligned}
$$

Substituting (4.3) into (4.2) gives

$$
P_{n}^{m}=\frac{(-1)^{\frac{n-m}{2}} m !(n+m) !}{2^{n}\left[\left(\frac{n+m}{2}\right) !\right]^{2}} C\left(\frac{n+m}{2}, \frac{n-m}{2}\right)
$$


for $n>0, m$ and $n$ of the same parity, and $m \leq n$. The remaining values of $P_{n}^{m}$ are given in [1] as $P_{0}^{0}=1$ and $P_{n}^{m}=0$ for $m$ and $n$ of different parity.

\section{REFERENCES}

1. HAGGARD, P.W. On Legendre Numbers, International Journal of Mathematics and Mathematical Sciences, Volume 8, No. 2 (1985) 407-411.

2. HAGGARD, P.W. Some Applications of Legendre Numbers, International Journal of Mathematics and Mathematical Sciences, (to appear).

3. RAINVILlE, E.D. Special Functions, The Macmillan Company, New York, 1960.

4. COPSON, E.T. An Introduction to the Theory of Functions of a Complex Variable, Oxford University Press, London, 1935.

5. RICHARDSON, C.H. An Introduction to the Calculus of Finite Differences, C. Van Nostrand Company, Inc., New York, 1954. 


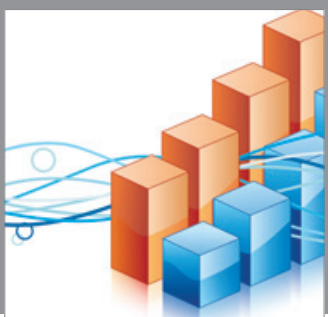

Advances in

Operations Research

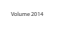

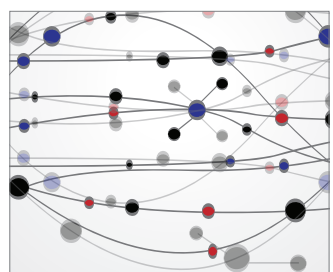

\section{The Scientific} World Journal
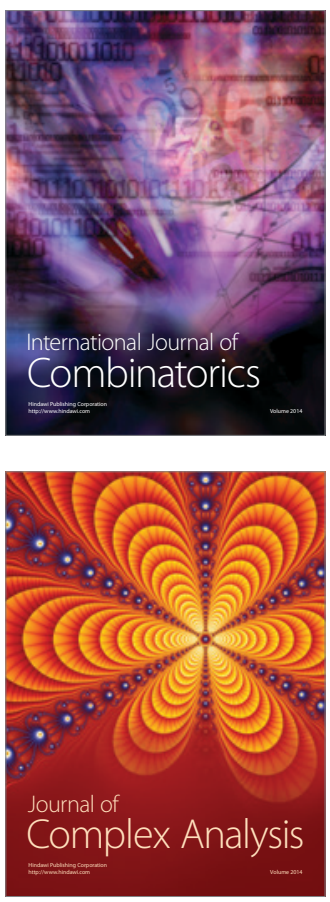

International Journal of

Mathematics and

Mathematical

Sciences
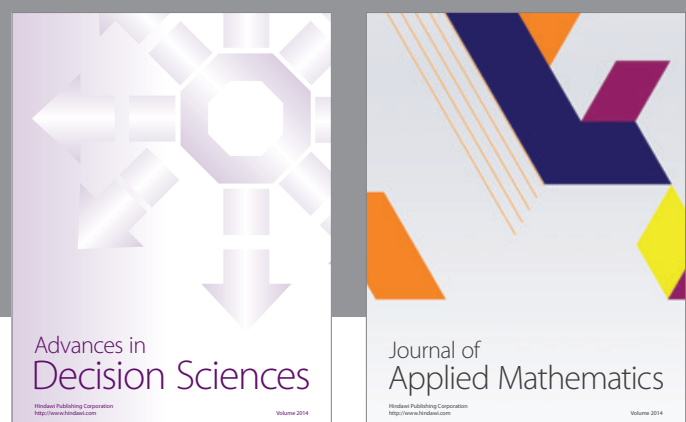

Journal of

Applied Mathematics
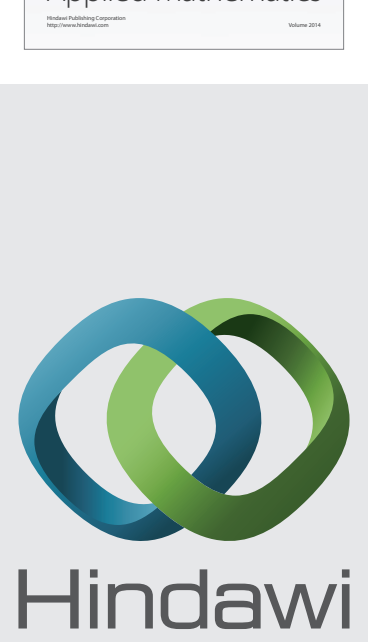

Submit your manuscripts at http://www.hindawi.com
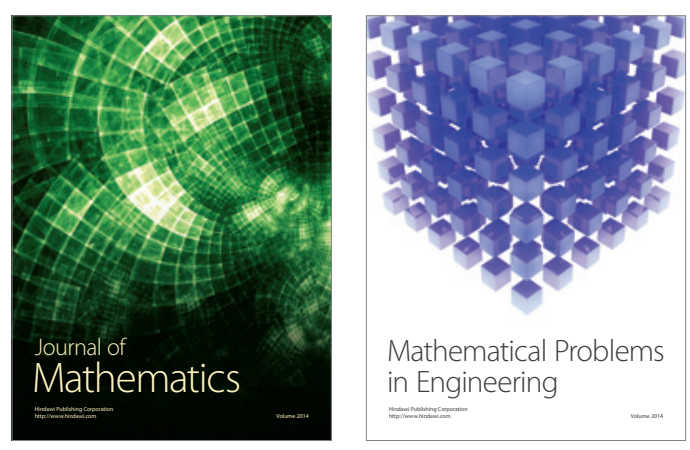

Mathematical Problems in Engineering
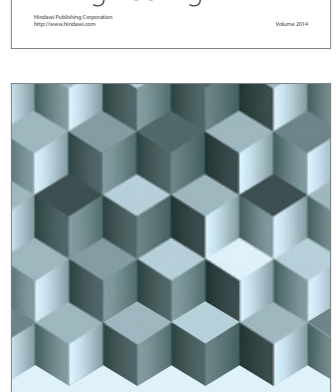

Journal of

Function Spaces
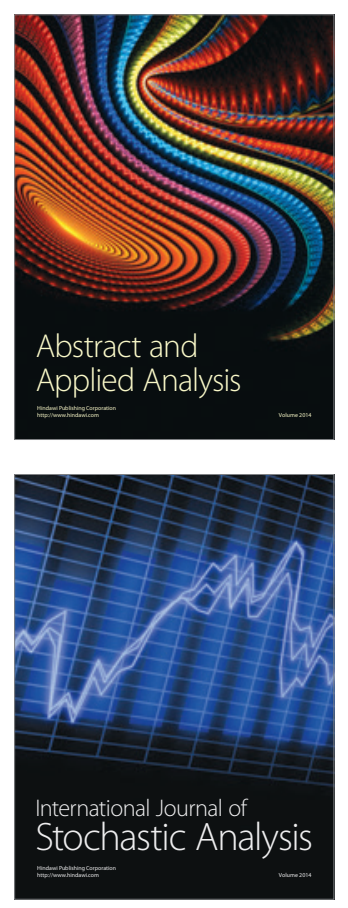

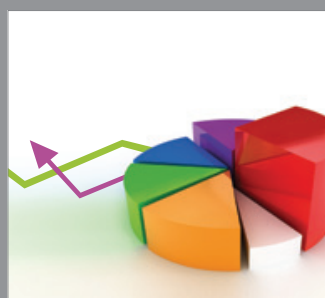

ournal of

Probability and Statistics

Promensencen
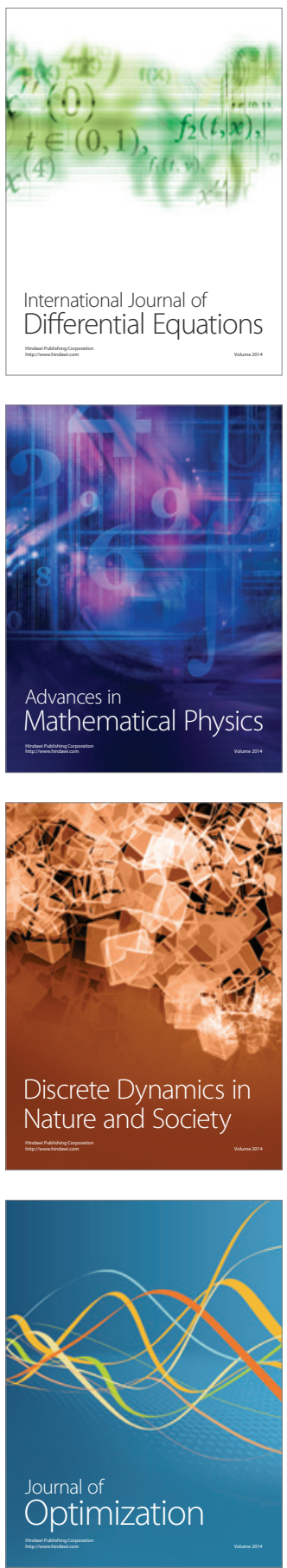